\title{
Correlation between social support, self-efficacy and health-promoting behavior in hemodialysis patients hospitalized in Karaj in 2015
}

\author{
Mahmoud Kiajamali ${ }^{1}$, Meimanat Hosseini ${ }^{2}$, Fatemeh Estebsari ${ }^{3}$, Maliheh Nasiri ${ }^{4}$, Tahereh Ashktorab ${ }^{5}$, \\ Amirhossein Abdi ${ }^{6}$, Aazam Mahmoudi ${ }^{6}$, Atefe Salimi Akin Abadi ${ }^{7}$
}

${ }^{1}$ M.Sc. in Community Health Nursing, Alborz Hospital, Alborz Province, Tehran, Iran

${ }^{2}$ Ph.D. in Nursing, Assistant Professor of Community Health Nursing Dept., Faculty Member of Nursing \& Midwifery School, Shahid Beheshti University of Medical Sciences, Tehran, Iran

${ }^{3}$ Ph.D. in Health Promotion and Education, Assistant Professor of Community Health Nursing Dept., Faculty Member of Nursing \& Midwifery School, Shahid Beheshti University of Medical Sciences, Tehran, Iran

${ }^{4}$ Ph.D. in Statistics, Assistant Professor of Biostatistics Dept., Shahid Beheshti University of Medical Sciences, Tehran, Iran

${ }^{5}$ Ph.D. in Nursing, Associate Professor, Faculty Member of Nursing \& Midwifery Dept., Shahid Beheshti University of Medical Sciences, Tehran, Iran

${ }^{6}$ M.Sc. in Nursing, Alborz Hospital, Alborz Province, Iran

${ }^{7}$ MSc Student in Medical Surgical Nursing, School of Nursing \& Midwifery, Shahid Beheshti University of Medical Sciences, Tehran, Iran

\section{Type of article: Original}

\begin{abstract}
Background: In hemodialysis, as a choice of treatment due to long treatment duration, the patient encounters limitations. Perceived social support, perceived self-efficacy and health promoting activities are important strategies to facilitate and maintain their health.

Aim: To determine the correlation between social support, self-efficacy and health promoting behaviors in hemodialysis patients hospitalized in Karaj city in 2015.

Methods: This cross-sectional descriptive correlational study was carried out on 200 hemodialysis patients who were selected from four hospitals in Karaj based on cluster sampling. Data were collected using these methods: "General Questionnaire", "Perceived Self-Efficacy Scale", "Multidimensional Perceived Social Support Scale" and "Health-Promoting Lifestyle Profile 2". Data were analyzed by SPSS version 22 and the EQS 6.1. Independent t-test, Mann-Whitney U, Kruskal-Wallis test, spearman correlation coefficient was used to analyze the data. To determine the relation between perceived self-efficacy, perceived social support and health promoting behavior, structural equation modeling was applied.

Results: Self-efficacy has a significant positive correlation with social support $(\mathrm{r}=0.592, \mathrm{p}<0.001)$ and significant negative correlation with health-promoting behaviors $(\mathrm{r}=-0.709, \mathrm{p}<0.001)$, and social support has a significant negative correlation with health-promoting behaviors $(\mathrm{r}=-0.709, \mathrm{p}<0.001)$. Also, results showed that perceived self-efficacy had a greater role than perceived social support in explaining health-promoting behaviors.

Conclusion: The relationship between health promoting behaviors, self-efficacy and social support reveals a necessity for Community Health Nursing planners, matrons and hospital managers and nurses to pay more attention to the needs of patients under hemodialysis. It is recommended that due to some unexpected findings in this study, further studies shall be fulfilled on the factors effective on the discussed variables.
\end{abstract}

Keywords: Social support, Self-efficacy, Health promoting behaviors, Patient, Hemodialysis

\section{Corresponding author:}

Assistant Professor Dr. Meimanat Hosseini, School of Nursing \& Midwifery, Shahid Beheshti University of Medical Science, Vali-Asr Avenue, Cross of Vali-Asr and Neiaiesh Highway, Opposite to Rajaee Heart Hospital, Tehran, Iran. Tel.: +989122394767, Fax: +982188655366, Email: meimanathosseini@yahoo.com, m-hoseini@sbmu.ac.ir Received: April 21, 2016, Accepted: March 25, 2017, Published: July 2017 iThenticate screening: March 25, 2017, English editing: June 12, 2017, Quality control: July 01, 2017

(C) 2017 The Authors. This is an open access article under the terms of the Creative Commons Attribution-NonCommercialNoDerivs License, which permits use and distribution in any medium, provided the original work is properly cited, the use is non-commercial and no modifications or adaptations are made. 


\section{Introduction}

Previously, chronic kidney disease (CKD) was merely a health issue, however, now it has developed into a global problem and threat (1). End-stage kidney disease (ESKD) can be defined by the requirement for life-saving dialysis or kidney transplantation. Worldwide, the number receiving renal replacement therapy (RRT) is estimated at more than 1.4 million, with incidence growing by approximately $8 \%$ annually. Worldwide, the number of patients with ESKD at the end of 2014 was estimated at around 3,346,000 people. By the year 2014, 2.358 million people in 36,000 dialysis centers worldwide had been treated. In Iran 25,934 ESKD patients had been treated with hemodialysis by the end of 2014. Medical and economic care in CKD is challenging. Hemodialysis annual growth is three percent in America and seven percent in Iran and the world average is $6.5 \%$ (2). The main treatment of chronic kidney disease is kidney transplant (3). This method has been the most expensive replacing treatment for a long time in Iran and all over the world since its annual expense is estimated to be 50,000 dollars in Europe, 23,000 dollars in Turkey and 10,000 dollars in Iran (1). The patients suffering from chronic kidney disorder under hemodialysis encounter limitation in daily activities, dependency to others, financial stresses, family problems, changes in life, mental image and dimensions of self-confidence. Due to long term treatment and occurrence of so many problems for the patients, attention of family members and friends is gradually decreased (4). Social support focuses on quality of relationships and Solidarity between individuals (5) and this is an experience that makes person believe that he is a valuable person in communicating and establishing a two-way relationship with others in a social network (6). Observations resulting from various studies demonstrate that social support plays a significant role in preserving people's health and will have a direct influence on decreasing negative effects of various stresses from environment and society, and consequently, on quality of life. By increasing the amount of social support, quantity of fatality is decreased and physical and psychological disorders are reduced (7). Conclusions obtained from studies by Aure'LieUntas et al., carried out on 32,332 patients under hemodialysis in 12 countries from 1996 to 2008 show that low level of social support in patients under hemodialysis causes an increase in fatality and decrease in life style, and patients seldom regard their regimen (8). Meanwhile, patients suffering from kidney disorder who are under hemodialysis treatment require a modification in their life style and self-sufficiency in the area of regimen. Self-sufficiency perception may intensify self-care activities and improve obedience to their regimen (4). Bandura believes that a person with low self-sufficiency may rarely make any effort to fulfill a new health behavior or to alter a behavior which they are used to (9). Self-efficacy is a person's belief about his or her ability and capacity to accomplish a task or to deal with the challenges of life (10). It is also referred to as personal efficacy, and is the extent or strength of one's belief in one's own ability to complete tasks and reach goals (9). Self-efficacy is related to feeling self-esteem, self-worth, and a sense of efficacy in life (10). Self-sufficiency can influence all aspects of life (11). Paying attention to health hazards together with personal life style are registered well in texts; and it is completely specified that health promoting activities and benefitting a safe life style are the significant strategies to facilitate and maintain health (12) and health care (13). Health-promoting behaviors are behaviors or actions that people carry out because they tend to improve their health status (14) and include responsibility for health, physical activity, nutritional behavior, sublimity of the soul (spiritual growth), interpersonal relationship and stress management (15). Health promotion leads to a significant decrease in expenses of health care in subsequent years (16). Health promotion has a vital role in increasing general policies of health and health-supporting environments, in increasing positive social conditions and individual skills and promoting safe living methods (17). Nowadays, there is a great emphasis on promoting health levels, welfare and self-care. Hence, predictions of the WHO demonstrate that 70 to $80 \%$ of mortality in developed countries and 40 to $50 \%$ of mortality in developing countries are due to diseases related to lifestyle. Because of the significance of this issue, in 2000, the WHO focused on healthy lifestyle, and furthermore, keeping and improving behaviors of healthy lifestyle was the most important objective of the organization.(18). Much research in Iran and other countries in the area of social support and selfefficacy in patients receiving hemodialysis are implemented $(2,4,8,10,11,18-22)$. In the field of self-efficiency; however, no study has been fulfilled regarding health promoting behaviors in patients receiving hemodialysis and/or its relation with self-efficacy and social support in these patients. Considering the ever-increasing escalation of patients receiving hemodialysis and their problems, it is required to have studies on perception of patients regarding social support, self-efficacy and health promoting behavior and reviewing effective elements on this perception. Therefore, the present study is performed in order to determine correlation of social support, self-efficacy and health promoting behaviors in patients under hemodialysis in hospitals in Karaj in 2015.

\section{Material and Methods}

\subsection{Research design and selection criteria}

This study was a cross-sectional descriptive correlational study. Sample size were determined as 165 based on the previous study (23) and assuming $r=0.25, \alpha=0.05$ and $\beta=0.10$. However, the final sample size was considered as 200 
individuals concerning the percent of non- response (20\%). 200 hemodialysis patients were selected from 4 hospitals in Karaj through cluster sampling method. This method is used for the study of populations in areas of broad geographic range (24). After certifying proposal, and receiving sampling license, four hospitals, which included 3 public hospitals and one hospital affiliated to Social Security Organization (clusters) among the eight centers, were selected based on having a dialysis ward and through geographic status. Then one of the researchers attended hospitals and introduced himself and the objectives of study, in coordination with directors of hospitals, and in two consecutive days per week at morning, evening and night shifts in the dialysis ward, he took action to present required descriptions about research and its goals while emphasizing on confidentiality of responses, and gained written letters of consent, and filled and collected the instruments through interview while the patients were connected to dialysis device. Inclusion criteria were as follows: 1) Being an Iranian national, 2) At least 18 -year-old, 3) It was at least one year since their first dialysis, 4) According to the medical profiles, they had no other disease, except the illnesses which lead to dialysis (blood pressure and diabetes), 5) They were aware of time and location and able to reply to the presented questions of the research, 6) They gave their consent to participate in the study, 7) They were able to speak Persian and they had fistula. Exclusion criterion was incomplete filling of the instruments.

\subsection{Instrument}

Data collection instruments in this research included the following:

2.2.1. "General Questionnaire" (17 questions):

In the general questionnaire, the variables of gender, age, education, marital status, employment, domicile, number of children, number of people living with the patient, income, age at first dialysis, duration of suffering from chronic disease of kidney, duration of performing hemodialysis, leading factor to hemodialysis, existence of other people under hemodialysis in the family of patient, receiving care from another person and the amount of independency of the patient were considered as interfering variables.

2.2.2. "Perceived Self-Efficacy Scale"(12 items, 7-option):

Perceived Self-Efficacy Scale has 12 items 7-options, and score shall be 12 and 84 in this scale, as minimum and maximum scores, respectively (25). According to the suggestion of the questionnaire planner in the present research, to maintain weight of items, an average of scores was used. Therefore, minimum and maximum averages of scores of scale are considered 1 and 7, respectively. Meanwhile, this scale has two subscales of adaptive self-efficacy and confronting self-efficacy.

\subsection{3. "Multidimensional Perceived Social Support Scale" (14 items, 7-options):}

This scale has 14 items 7 -options of Likert from 1 to 7 scores for each item (completely agreed=7 to completely disagreed=1), with minimum score of 14 and maximum score of 98 which was designed by Hosseini, and obtaining higher score shows higher perceived support (25). Based on the suggestion of the planner of the scale, to preserve weight of scale items, average of scores (1 to 7) were used. Also, this scale has three subscales of support of family and authorities, support of relatives and support of friends.

\subsection{4. "Health-Promoting Lifestyle Profile 2" (including 52 items, 4-options):}

Health-Promoting Lifestyle Profile 2 was designed to review health promoting behaviors. These behaviors include spiritual growth, health responsibility, physical activity, nutrition, interpersonal relationship and stress management. This scale was designed by Walker et al. (26) with minimum 52 and maximum 208 scores.

\subsection{Validity and reliability}

Validity of "general questionnaire" was specified qualitatively and validity of "Perceived Self-Efficacy Scale" and "Multidimensional Perceived Social Support Scale" was determined through two quantitative (content validity index and content validity ratio) and qualitative (written or oral comment) methods (25), and its amounts were reported properly. Health-Promoting Lifestyle Profile 2" which was used to assess health promoting behaviors of samples, was also translated and its psychometric properties were assessed; and its extent was reported to be appropriate (27). Cronbach's Alpha was 0.72 and 0.76 for "Multidimensional Perceived Social Support Scale" and "Perceived SelfEfficacy Scale" respectively. In the present study Cronbach's Alpha was 0.75 for Health-Promoting Lifestyle Profile 2.

\subsection{Statistical analysis}

Data were analyzed by SPSS, version 22 and the EQS 6.1. To analyze data descriptive statistics (mean, standard deviation and percent frequency) and the Kolmogorov-Smirnov test, parametric statistical tests (t-test, Pearson correlation coefficient), nonparametric tests (Man-Whitney U, Kruskal-Wallis and Spearman correlation coefficient) was performed. In order to determine the fit model, self-efficacy and perceived social support and health promoting behaviors structural equation model was used. 


\subsection{Ethics of research}

All of the subjects were informed regarding the details of the study and they signed a written informed consent. This study was approved by the Ethics Committee of Nursing and Midwifery School of Shahid Beheshti University of Medical Sciences with the registration number of SBMU2.REC.1394.50 in 2015.

\section{Results}

Results of this study concerning demographic characteristics of the samples, demonstrated that out of 200 participating patients in the study, $55.50 \%$ of them were male. Their age average was 58.92 years and standard deviation was 11.156 . In total, $37.50 \%$ of the patients were aged between 56 to 65 years old. Furthermore, $31.50 \%$ of the patients were illiterate, $81.00 \%$ were married and $41.50 \%$ were housewives. A total of $98.50 \%$ of the patients lived in the city and $45.00 \%$ had $4-6$ children. Also, $93.50 \%$ of the patients lived in families with 1 to 5 other members. Of all the patients, $75.00 \%$ of them had no sufficient monthly income and $81.00 \%$ of the patients had been under hemodialysis after 46 years of age. It was from one to ten years that most of them $(89.50 \%)$ had experienced chronic disease of the kidney and $76.00 \%$ of them had been under hemodialysis from one to five years. Furthermore, $47.5 \%$ of patients suffered from both hypertension and diabetes, $99.00 \%$ of them had no other family member under hemodialysis, $89.00 \%$ of the patients were under care of another person and $47.00 \%$ of them were relatively independent. Some of the characteristics of the research samples are presented in Table 1. Concerning relationship of quantitative demographic variables with main variables of research which are observed in Table 2, age has a positive correlation with self-efficacy and perceived social support, and has a significant negative correlation with health promoting behaviors $(\mathrm{p}>0.01)$. Duration of infection to a chronic disease of kidney has a positive correlation with health promoting behaviors, and negative correlation with perceived social support and perceived self-efficacy. Statistically, there is only a significant relationship between perceived self-efficacy and duration of infection to chronic disease of kidney $(\mathrm{p}>0.01)$. Education status has a negative correlation with selfefficacy and social support, and significant positive correlation with health promoting behaviors $(p>0.01)$. The number of children has a positive correlation with self-efficacy and social support and a negative correlation with health promoting behaviors, which seems to be statistically significant $(\mathrm{p}>0.01)$. The number of people living with the patient has a negative correlation with self-efficacy and social support and a negative correlation with health promoting behaviors, which could be statistically significant in social support ( $p>0.05)$. Age at first hemodialysis has a positive correlation with self-efficacy and social support and a negative correlation with health promoting behaviors $(\mathrm{p}>0.01)$. Income amount has a positive correlation with self-efficacy and social support and a negative correlation with health promoting behaviors $(\mathrm{p}>0.01)$.

Table 1. Distribution of frequency of personal characteristics of units under study

\begin{tabular}{|c|c|c|}
\hline \multicolumn{2}{|l|}{ Variables } & $\mathrm{n}(\%)$ \\
\hline \multirow{2}{*}{ Gender } & Female & $89(44.50)$ \\
\hline & Male & $111(55.50)$ \\
\hline \multirow{2}{*}{ Marital Status } & Married & $162(81.00)$ \\
\hline & Single & $38(19.00)$ \\
\hline \multirow{5}{*}{ Age Group (year) } & $\leq 45$ & $26(13.00)$ \\
\hline & $46-55$ & $46(23.00)$ \\
\hline & $56-65$ & $75(37.50)$ \\
\hline & $66-75$ & $42(21.00)$ \\
\hline & $>75$ & $11(3.50)$ \\
\hline \multirow[t]{6}{*}{ Working Condition } & Housewife & $83(41.50)$ \\
\hline & Worker & $5(2.50)$ \\
\hline & Employee & $3(1.50)$ \\
\hline & Self-Employed & $12(6.00)$ \\
\hline & Unemployed & $35(17.50)$ \\
\hline & Retired & $62(31.00)$ \\
\hline \multirow[t]{5}{*}{ Education } & Illiterate & $63(31.50)$ \\
\hline & Primary School & $52(26.00)$ \\
\hline & Guidance School & $36(18.00)$ \\
\hline & Secondary School & $36(18.00)$ \\
\hline & Academic studies & $7(3.50)$ \\
\hline
\end{tabular}


Duration of performing hemodialysis has a positive correlation with self-efficacy and social support and a negative correlation with health promoting behaviors that self-efficacy and health promoting behaviors are meaningful statistically $(p>0.05)$. Concerning the relation of main variables with each other in this research, as it is seen in Table 3, using the Spearman test, perceived self-efficacy has a positive and significant correlation with perceived social support and has a negative significant correlation with health promoting behaviors, and perceived social support has a negative significant correlation with health promoting behaviors ( $p>0.01)$. As can be observed in Figure 1, through explaining health promoting behaviors, perceived self-efficacy had a more significant role comparing perceived social support. Meanwhile, subscale of contrasting self-efficacy could determine health promoting behaviors more than adaptive self-efficacy, and support of friends had the least role in specifying health promoting behaviors.

Table 2. Spearman correlation coefficient of Perceived Self-Efficiency, Perceived Social Support and Health Promoting Behaviors with Demographic Quantitative Variables in Research Samples

\begin{tabular}{|l|l|l|l|}
\hline Variable & Perceived Self-Efficiency & $\begin{array}{l}\text { Perceived Social } \\
\text { Support }\end{array}$ & $\begin{array}{l}\text { Health Promoting } \\
\text { Behaviors }\end{array}$ \\
\hline Age & $*_{0.579}$ & $*_{0} 0.453$ & $*_{-}-0.522$ \\
\hline Disease duration & $* *_{0} 0.074$ & -0.004 & -0.087 \\
\hline Education & $*_{-} 0.329$ & $*_{-} 0.186$ & $*_{0} 0.331$ \\
\hline Number of children & $* *_{0} 0.357$ & $*_{-} 0.305$ & $* *_{-}-0.394$ \\
\hline Number of people living with patient & -0.98 & $*_{-} 0.0157$ & 0.088 \\
\hline Age at first hemodialysis & $* *_{0} 0.565$ & $*_{0} 0.445$ & $*_{-}-0.507$ \\
\hline Income level & $* *_{0.254}$ & $*_{0} 0.286$ & $*_{-}-0.043$ \\
\hline Hemodialysis duration & $*_{0.162}$ & 0.102 & $*_{-}-0.154$ \\
\hline
\end{tabular}

* Correlation is significant at $0.05, * *$ Correlation is significant at 0.01

Table 3. Correlation between Perceived Self-efficacy, Perceived Social Support and Health Promoting Behaviors

\begin{tabular}{|l|l|l|l|}
\hline Variable & Perceived Self-Efficacy & Perceived Social Support & Health Promoting Behavior \\
\hline Perceived Self-Efficacy & 1 & & \\
\hline Perceived Social Support & $* * 0.592$ & 1 & \\
\hline Health Promoting Behavior & $* *-0.709$ & $* *_{-} 0.709$ & 1 \\
\hline
\end{tabular}

**Correlation is significant at 0.01



Figure 1. Determining measuring model of perceived self-efficacy, perceived social support and health promoting behaviors in research samples. $\mathrm{CFI}=0.97$, GFI $=0.86, \mathrm{NFI}=0.96, \mathrm{RMSEA}=0.13$. Note: Standardized coefficients are among 1 and -1 , these values are closer to 1 or -1 , stronger correlation and relationship. If RMSEA index is closer to zero, and the rest of the indexes are closer to 1, it shows better and more appropriate fitness of the model. 


\section{Discussion}

Results of this study specified relationship of self-efficacy, social support and health promoting behaviors with each other and with demographic variables in patients receiving hemodialysis under study. Concerning correlation of selfefficacy, social support and health promoting behavior, results show that self-efficacy has a positive and significant correlation with social support and has a negative significant correlation with health promoting behaviors, and social support has negative significant correlation with health promoting behaviors. In a study about health promoting behaviors in Thai people suffering from Chronic Disease of Kidney, there was a positive relation between perceived self-efficacy and social support and health promoting behaviors, and among all independent variables and health promoting behaviors, the strongest correlation was between perceived self-efficacy and health promoting behaviors (28). According to the implemented studies concerning social support and self-efficacy in patients under hemodialysis, these two variables have a positive relation with each other in the present study, however, it has a significant negative relation with health promoting behaviors, on the contrary to the study executed by Polsingchan, in which social support had a significant positive relation with health promoting behaviors (28); and it can be interpreted that higher self-efficacy and social support of patients, can imply less necessity for health promotion However, according to the researchers, considering the questions about scales, it seems that patients' answers to questionnaires of perceived social support and perceived self-efficacy are subjective and propagandist and idealistic, and patients may reply to some questions based on their thoughts and prejudices and expectations, and they can never encounter them objectively. In other words, patients may perceive ideal and not real and existing situations. But questions of the questionnaire about health promoting behaviors were more realistic, objective, tangible and functional, and are connected to the daily life of the patient, and considering the physical and mental status of such patients, who are considered as special patients, answers seem to be logical and believable. Furthermore, through determining correlation coefficients between social support, self-efficacy and health promoting behaviors in the patients receiving hemodialysis at hospitals, demonstrated that variable of perceived self-efficacy had a more significant role in specifying health promoting behaviors proportional with perceived social support. Also, contrasting self-efficacy can influence health promoting behaviors more than adaptive self-efficacy, and support of friends had the least role in determining health promoting behaviors. No similar study has been found in this area. Findings of the present study show that health promoting behaviors were perceived moderately by $68.0 \%$ of patients, self-efficacy by $39.5 \%$, and social support by $45.00 \%$ of patients. Zamanzadeh et al. expressed that concerning aspect of social support, studies show that $49.4 \%$ of the units under study had undesired social support and $50.60 \%$ of them had desired social support (7). Differences in findings may be related to method of classification of scores, that they were divided into 4 groups but in the present study, separated into 2 groups. Results of studies performed in the area of social support in the patients with chronic disease demonstrated that about one third of samples reported low social support (29). These studies were carried out in Switzerland which shows more desirable emotional support compared with the present study, and it seems that the reason for higher emotional support in the said research may be due to consistent and effective support of that country, governmental plans, better welfare situation of patients, their access to more facilities and conveniences during their illness. Results of the Zamanzadeh et al. study in this area showed that the family gives the most support to patients, while welfare organizations which support patients can never attract patients' consent and support them (7). Findings about self-efficacy in patients under hemodialysis demonstrated that $71.4 \%$ of samples had a moderate self-efficacy level (11). This result is in line with the present study, so that identical to the present study, self-efficacy of the majority of patients was moderate. In the study about determining general status of social support $59.5 \%$ of patients received undesirable social support (8). The outcome of other studies also gained the same results as these results (7, $30,31)$. Contrary to this, in the study, social support was perfect in $82.1 \%$ of patients (32); also in the study of Mollaoglu most of the patients benefitted from desirable social support (33). This difference of the findings with the present study can be related to the classification method of scores which are divided into 4 groups in the present study and into 2 groups in the said studies. Haririan et al. cited from Melisa et al. that there is a direct relation between low social support and mortality of the patients receiving hemodialysis, so that decrease in social support may lead to increase in mortality of patients under hemodialysis up to $10 \%$ (8). Considering the present study, it can be observed that there is a similar relation between social support and self-efficacy in the patients receiving hemodialysis, no other study was observed concerning the relation of these two variables in the patients under hemodialysis. No research was found concerning health promoting behaviors in the patients under hemodialysis. In this regard, Polsingchan writes: "Study on health promoting behavior on the patients suffering from chronic disease of kidney and the patients receiving hemodialysis are so low, that more research is required to be executed to expand our knowledge about health promoting behavior and its relevant elements; such studies can present information concerning perception of health promoting behaviors (28). Moreover, the research can be a basis for the development of interventional methods to assist people suffering from chronic disease of kidney and to help the 
studies related to health and treatment activities and to facilitate health promoting behaviors for people suffering from chronic disease of kidney. Furthermore, such research can present an intercultural test of health promoting behaviors which may cause improvement at its declarative value in describing the behaviors related to health in all cultures, and finally, increase in predictions can lead to a comprehensive theory with a special cultural structure.

\section{Research Limitations}

Spiritual and mental status of patients during completion of the questionnaire was out of the researcher's control, and it was also probable that samples under study avoided reflecting their true feelings in replying to questions, thus by describing that content of questionnaire was completely confidential, and there was no need to pronounce name and surname, this case was somehow controlled. Also, with the amount of questions being so many, patients may have become bored or disinterested, thus the questionnaire was completed by a researcher through interview. Influence of the presence of the researcher and completion of the relevant instruments by the researcher which may lead to presenting community-oriented replies or shame or prudency in answers were among other inevitable limitations of this study; specifically considering the fact that there were so many illiterate and low-literacy people in the samples of the research.

\section{Conclusions}

Considering the findings of the present study, and regarding the role of health promoting behaviors, self-efficacy and social support in patients under hemodialysis which impact on treatment procedure and quality of life of these patients, it seems that educational intervention is required based on theories of change in behavior and also presenting training of life skills and ability of compatibility, along with training of key concepts of self-efficacy and social support and their perception in order to empower patients (theoretically and functionally).

\section{Acknowledgments:}

The present article is the result of a final thesis advised by Dr. Meimanat Hosseini and the research project ratified by Shahid Beheshti University of Medical Sciences under code of SBMU 2. Rec. 1394.50. Finally, we hereby take the opportunity to express our gratitude to all instructors and bodies who assisted us in the performance of the present study, particularly authorities of the hospitals under study and the valued patients who participated in this research.

\section{Conflict of Interest:}

There is no conflict of interest to be declared.

\section{Authors' contributions:}

All authors contributed to this project and article equally. All authors read and approved the final manuscript.

\section{References:}

1) Najafi A. Peritoneal dialysis in Iran \& world. Tehran, Pelk Publication (2013): 36

2) Iran dialysis consortium. Iranian Dialysis Almanac. 2015.

3) Zeighami Sh, Asadifard F, Babaheidari TB. Distressing symptoms among patients the chronic renal failure undergoing hemodialysis and its relationship with quality of life. Iranian Journal of Critical Care Nursing. 2013; 5(3): 191-8.

4) Rambod M, Rafiei F. Perceived social support in the patients under hemodialysis. Journal of Faculty of Nursing \& Midwifery of Iran University of Medical Sciences (Iran Nursing Journal). 2009; 55(58): 99-110.

5) Stanhope M, Lancaster J. Foundation of nursing in community, community oriented Practice. 2ndedition.Mosby Elsevier Co. 2006.

6) Marmot M, Wilkinson R. Social determinants of health. 2005. Book. books.google.com.

7) Zamanzadeh V, Heidarzadeh M, Ashvandi K, Lakdizaji S. Correlation between quality of life and social support in the patients under hemodialysis. Tabriz University of Medical Sciences Journal. 2006; 29(1): 49-54

8) Haririan H, Aghajanlou A, Ghafourifard M. Study of social support in hemodialysis patients in Zanjan, Medical Sciences. Journal of Islamic Azad University. 2013; 23(1): 74-80.

9) Bagheri Saveh MA. Study of correlation of self-efficacy with self-care behaviors in patients suffering from cardiovascular congestive disorder hospitalized in cardiovascular internal wards of Tohid Hospital in Sanandaj, affiliated to Kordestan University of Medical Sciences in 2011. M.Sc. Final Thesis 2012:8-9 \&11.

10) Abdollahi B. Role of self-efficacy in personnel empowerment. Tadbir Journal. 2006; 16(8): 35-40.

11) Esmaeili M, Alikhani M, Gholam Araghi M, Hosseini F. Quality of life and it relation with self-efficacy in patients under hemodialysis. Iran Nurses Journal. 2005; 18 (41 \& 42): 84-77. 
12) Haddad L, Kane D, Rajacich D, Cameron S, Al-Ma'aitah R. A comparison of health practices of Canadian and Jordanian nursing students. Public Health Nurs. 2004; 21(1): 85-90. doi: 10.1111/j.15251446.2004.21112.x. PMID: 14692993.

13) Hosseini M, Ashktorab T, Taghdisi MH, Vardanjani AE, Rafiei H. Health-promoting behaviors and their association with certain demographic characteristics of nursing students of Tehran city in 2013. Glob J Health Sci. 2014; 7(2): 264-72. doi: 10.5539/gjhs.v7n2p264. PMID: 25716384, PMCID: PMC4796448.

14) Peterson SJ, Bredow TS. Middle ranged theories: application to nursing research. USA. Philadelphia. Lippincott Williams \& Wilkins. 2004; 288-301.

15) Hosseini M, Sarbakhsh P, Ghasemi S, Parvizy S.Health-promoting behaviors in persons admitted to the health center selected in Tehran.Journal of Research \& Health. Social Development \& Health Promotion Research Center. 4 (2): 687-93.

16) W.H.O. Health promotion about us. (a) 2012. http://www.who.int. /entity/ Health promotion/about/ en /

17) Mohammadian H, Eftekhar Ardebili H, Rahimi Foroushani A, Taghdisi MH, Shojaei Zadeh D. Evaluation of Pender health promotion model in predicting living quality of adolescent girls. Journal of Faculty of Health \& Health Research Institute. 2011; 8(4): 1-13.

18) Salehi K, Mahmoudifar Y. Review of relation of social support with anxiety and depression in the patients under hemodialysis in Imam Khomeini Hospital. Mahabad, Nursing Studies. 2014; 9(1): 33-9.

19) Cheng Y, Liu C, Mao C, Qian J, Liu K, Ke G. Social support plays a role in depression in parkinson disease: a cross-sectional study in a Chinese cohort. Parkinsonism Relat Disord. 2008; 14(1): 43-5. doi: 10.1016/j.parkreldis.2007.05.011. PMID: 17616476.

20) Thong MS, Kaptein AA, Krediet RT, Boeschoten EW, Dekker FW. Social support predicts survival in dialysis patients. Nephrol Dial Transplant. 2007; 22(3): 845-50. doi: 10.1093/ndt/gfl700. PMID: 17164318.

21) Shakibazadeh E, Rashidian A, Larijani B, Forouzanfar MH, Karimi Shahanjarini A. Correlation between self-efficacy and perceived obstacles with self-care performance in the patients suffering from diabetes type 2. Journal of Faculty of Nursing and Midwifery, Tehran University of Medical Sciences, Hayat Quarterly. 2009; (4): 69-78.

22) Iskender $M$. The relationship between self-compassion, self-efficacy, and control belief about learning in Turkish University Students. Social Behavior and Personality, an International Journal. 2009; 37(5): 711 20. doi: 10.2224/sbp.2009.37.5.711.

23) Tel H, Tel H. Quality of life and social support in Hemodialysis patients. Pakistan Journal of Medical Sciences. 2011; 27(1): 64-7.

24) Abedsaeedi JH, Akbari AS. Research methods in medical science and health. Tehran, Salemi Publishing. 2006.

25) Hosseini M. Health promoting behaviors \& its related factors in nursing students in the Tehran Universities: Pender model test, Ph.D. Thesis, Shahid Beheshti University of Medical Sciences. 2013.

26) Walker SN, Sechrist KR, Pender NJ. The Health Promoting life style profile. Development and psychometric characteristics. Nurs Res. 1987; 36(2): 76-81. doi: 10.1097/00006199-198703000-00002. PMID: 3644262.

27) Hosseini M, Yaghmaee F, Hosseinzadeh S, Alavimajd H. Translation and psychometric evaluation of Persian version of health promoting life style profile 2. Research Project of Faculty of Nursing \& Midwifery. Shahid Beheshti University of Medical Sciences. 2010.

28) Polsingchan S. Health-promoting behaviors in Thai persons with chronic renal failure. Dissertation Presented to the Faculty of the Graduate School of The University of Texas at Austin in Partial Fulfillment of the Requirements for the Degree of Doctor of Philosophy. The University of Texas at Austin. 2010.

29) Kristofferzon ML, Lofmark R, Carlsson M. Copping, social support and quality of life over time after myocardial infarction. J Adv Nurs. 2005; 52(2): 113-24. doi: 10.1111/j.1365-2648.2005.03571.x. PMID: 16164472 .

30) Yu HD, Petrini MA. The HRQol of Chinese patients undergoing hemodialysis. J Clin Nurs. 2010; 19(5-6): 658-65. doi: 10.1111/j.1365-2702.2009.03071.x. PMID: 20500307.

31) Al-Arabi S. Quality of life: subjective descriptions of challenges to patients with end stage renal disease. Nephrol Nurs J. 2006; 33(3): 285-92. PMID: 16859200.

32) Heidarzadeh M, Ghahremanian A, Haghighat A, Yoosefi E. Relationship between quality of life and social support in stroke patient. Iran Journal of Nursing. 2009; 22(59): 23-32.

33) Mollaoglu M. Perceived social support, anxiety and self-care among patients receiving hemodialysis. Dial Transplant. 2006; 35(3): 144-55. doi: 10.1002/dat.20002. 